University for Business and Technology in Kosovo

UBT Knowledge Center

UBT International Conference

2015 UBT International Conference

Nov 7th, 9:00 AM - 5:00 PM

\title{
Benefits of twinning programs: The case of Macedonia
}

Jasminka Varnalieva

International Balkan University, j.varnalieva@yahoo.com

Violeta Madzova

International Balkan University, v.madjova@ibu.edu.mk

Follow this and additional works at: https://knowledgecenter.ubt-uni.net/conference

Part of the Business Commons

\section{Recommended Citation}

Varnalieva, Jasminka and Madzova, Violeta, "Benefits of twinning programs: The case of Macedonia" (2015). UBT International Conference. 30.

https://knowledgecenter.ubt-uni.net/conference/2015/all-events/30

This Event is brought to you for free and open access by the Publication and Journals at UBT Knowledge Center. It has been accepted for inclusion in UBT International Conference by an authorized administrator of UBT Knowledge Center. For more information, please contact knowledge.center@ubt-uni.net. 


\title{
Benefits of twinning programs: The case of Macedonia
}

\author{
Jasminka Varnalieva $^{1}$, Violeta Madzova ${ }^{2}$ \\ 1,2International Balkan University, Skopje \\ j.varnalieva@yahoo.com¹,v.madjova@ibu.edu.mk ${ }^{2}$
}

\begin{abstract}
Twinning instrument is used for cooperation and long-term institutional partnership between public administrations of one or more EU Member States and the national authorities of beneficiary country. The purpose of this paper is to examine benefits of twinning programs as instruments for capacity building of public institutions. The paper provides an analysis of the twinning program portfolio in Macedonia per sectors, twinning country providers, and beneficiary institutions. The conclusions are that Macedonian institutions have benefitted a lot from the twinning programs implemented in the last fifteen years; nevertheless, there is still room for significant improvements in the design and implementation procedures that would enable the beneficiary institutions to take full advantage of these programs.
\end{abstract}

Keywords: Twinning, capacity building, institutions.

\section{Introduction}

Twinning is an instrument used for cooperation and long-term institutional partnership between public administrations of one or more EU member states and the national authorities of beneficiary country. For the pre-accession countries, Twinning is an instrument focused on providing support for transposition, implementation and enforcement of EU legislation. It is also used for sharing good practices developed within the EU with beneficiary public administration. Launched in 1998, twinning projects are built around EU policy objectives agreed between the public authorities of beneficiary country and the member states. Twinning aims to help the beneficiaries in the development of modern and efficient administrations, with the structures, human resources and management skills needed to implement the EU acquis.

In addition to the regular Twining instrument, Twinning Light is designed to provide a more flexible and mid-term assistance (up to 6 months) without a presence of resident twinning advisor (RTA) in the beneficiary country.

\section{Twinning versus technical assistance}

In terms of selecting the assistance instrument -- twinning versus technical assistance, the main three criteria used as best practice are applied in Macedonia, and there is no need to divert from them. So, when the (i) assignment is acquis related, (ii) the beneficiary is an established and mature institution with a clear choice on how to implement the acquis, and (iii) the beneficiary has the capacity to effectively co-operate with the twinning partners, the twinning instrument would be a good choice. Institutions in Macedonia have not used the cost-benefit analysis to make a decision on which instrument is most appropriate. Although cost-benefit analysis is not a formal requirement in the selection process, such analysis could provide additional information on advantages of using one instrument instead of the other, thus reinforcing the decision.

In the early phase of introducing the twinning instrument in Macedonia, the authorities did not have experience and sufficient knowledge on the benefits and opportunities of the use of twinning, so the European Agency for Reconstruction had to convince the institutions to start using this instrument. However, after a decade of experience in actual implementation of more than 60 twinning projects, the institutions in Macedonia now have a much better understanding of the features of twinning instrument, so they are in position to clearly recognize the advantages and weaknesses of using 
twinning and technical assistance, and they have a liberty to use the most appropriate instrument for the specific purpose. Procedures for preparation and monitoring of the twinning projects are very clearly outlined in the Twinning Manual. The Manual also provides templates for all documents that need to be prepared during the preparation, implementation and post-review of the projects. Macedonian authorities familiar with the twinning instrument are well aware of these procedures and use them as a proper tool in designing, implementation and monitoring of the twinning projects.

Twinning projects are results driven projects that provide very good, practical knowledge and best practices from similar institutions. This allows the Macedonian institutions to learn from the experience of the others while building long-term partnership with a "sister" institution. Twinning projects produce tangible (mandatory) results and intangible results for the beneficiary, and building partnership and changing the mindset of the staff and the organizational culture of the beneficiary institution are just some of them.

However, after a decade of experience in actual implementation of more than 60 twinning projects, the institutions in Macedonia now have a much better understanding of the features of twinning instrument, so they are in position to clearly recognize the advantages and weaknesses of using twinning and technical assistance, and they have the liberty to use the most appropriate instrument for the specific purpose. When choosing a twinning instrument readiness of the beneficiary institution to allocate sufficient number of appropriate people to work closely with the twinning resident advisor and various experts visiting the country is critical for the success of the project. In addition, the host institution should be ready do its homework well in advance, i.e. to decide what exactly it wants to achieve with the twinning project, to explore which member state institution would make the best fit for its needs, and to make a firm commitment to allocate appropriate resources to effectively implement the twinning project.

Beneficiary institutions also have in mind that twinning projects are much more demanding on their part, requiring their staff to be fully engaged with the resident twinning advisor and visiting experts for a long period of 12 - 24 months. This however, increases the ownership and provides satisfaction of the pro-active staff that they are able to learn a lot using "learning by doing" approach. For example the Statistical Office of Macedonia has been very satisfied with their twinning project that allowed them (in the case of national accounts data processing) to use Macedonia's statistical data to be processed with a new methodology. In this way, a number of calculations have been completed and new methodology has been introduced and already put in use. In addition, the actual presence of the resident advisor and frequent visits of the short term experts provide the beneficiary institution staff the opportunity to exchange opinions and different experiences with the twinning partner team on a daily basis which adds a lot of value for the professional development and overall capacity building of the institution. These professional and personal relationships tend to continue much longer after the actual twinning project is completed.

The technical assistance projects typically leave the beneficiaries more passive, waiting for the work to be completed by the TA providers, and then either using it to make most out of it, or using it according to their capabilities and priorities.

In terms of budget and decision making related to financial resources, Macedonian beneficiaries believe that in the technical assistance projects they have a bigger decision power compared to the twinning projects when most of the budget issues are decided and managed by the Member State counterparts. This however could still be addressed during the programming stage and work plan drafting activity. In terms of flexibility, the technical assistance projects typically provide for higher level flexibility, although with the recent changes in the twinning projects implementation, the flexibility has been significantly increased by quick processing of the "side letters" allowing for changes in the Work Plan. One of the advantages of the twinning projects from the beneficiary point of view is that in the preparation stage, it is easy to draft a project fiche, compared to the Terms of Reference (TOR) required for the technical assistance. Some of the beneficiary institutions in Macedonia still lack capacity to draft a high quality TOR, so they turn to donors or other methods to use external knowledge in drafting TOR. The quality of TOR is critical for obtaining the best and most effective technical assistance.

In terms of the selection of provider process, beneficiaries in Macedonia find the opportunity to have a verbal presentation of all proposals related to the twinning projects to be very useful, since it gives the possibility to meet the actual project leader in person, as well as to raise all questions important for a successful implementation of the project. In the TA selection process, verbal presentation is not required and typically it is not done, so the beneficiaries rely on written proposals only. On the other 
hand, the TA proposals are much more detailed and do not require additional time to be spent in detailing the work plan once the provider is being selected. The beneficiary institutions could however request a verbal presentation of the TA proposals as well, although it is not a formal requirement. Also, when choosing the twinning provider, having the body of knowledge and experience of an old member state institution coupled with pre-accession experience of a new member state institution has proven to be the formula for success that provides the best platform for assistance to Macedonian counterparts. For the twinning projects, the process starts with drafting the project fiche. This is very important step that will shape the overall project, the outputs, the activities and the outcome of the project. Macedonian beneficiaries recognize the significance of drafting a high quality fiche, given that the most important issue that needs to be addressed in this stage is to determine very clearly what exactly the need of the institution is. This is related to defining the objective of the project, guaranteed results expected from the project, profile of experts and resident advisor, etc. It is also important to explore and find out which institution is the best fit for the project, in terms of specific experience, capacity building, and value added.

To achieve best outcome of the project, it is very important to incorporate all stakeholders that are relevant for achieving the project purpose and mandatory results. For example, the twinning project in the Ministry of Agriculture, Forestry and Water Economy focused on the organic agricultural production and quality protection of agriculture products worked with twelve different stakeholders in Macedonia to achieve the project purpose. Given the complexity and scope of the project, the project team assisted the producers (through their associations), standardization and accreditation bodies, different inspectorates, food and veterinary agency, phyto-sanitary laboratory, line ministry etc., and in this way covered the entire supply chain of organic production and quality protection system. Although it is not always easy to coordinate and work with such a big number of stakeholders, it is essential to incorporate all relevant parties to achieve full success of the process.

Another important feature in terms of implementation is the commitment of the beneficiary institutions and the people involved. Macedonian institutions are aware of the level of commitment and input expected on their side from the very start of the twinning project (including the fiche and work plan drafting processes). Still, having in mind the knowledge and expertise they are expecting from the twinning counterparts, they have been ready to dedicate extra time and efforts to accept this new knowledge. The transfer of knowledge is carried out not only through the formal trainings, study tours and other activities, but also through continuous discussions and exchange of views with various experts. Some of the twinning partners shared their most updated methodologies that are now used in the beneficiary institutions. All of these efforts result in change of organizational culture and sometimes in organizational structures of the beneficiary institutions.

Once a beneficiary institution goes through a successful twinning project (and gets a firsthand experience on how it should be done), it is much easier for them to prepare for another twinning project. Twining projects are financed by EU grants; however, the beneficiary country has a responsibility to provide small co-financing. Providing the co-financing is usually not a problem for Macedonia, however, sometimes during the implementation process, the Beneficiary institution faces a problem to provide funds to finance particular activities already being incorporated in the Work Plan. Beneficiary institutions should ensure that the necessary funds are allocated in their annual budgets. Some Macedonian institutions have implemented twinning projects incorporating small TA projects, particularly for developing IT solutions and for using the local knowledge on the Macedonian accounting and auditing standards and practices. These projects have been carried out smoothly with very good results. To summarize, both technical assistance and twinning projects can provide very good results. To achieve that, the beneficiary institution needs to have a very clear idea of the intervention logic, and results that need to be achieved. In addition, selecting the best twinning or TA provider is also very important. In the case of twinning, creating a close personal relationship could play a very important role in the success of the project.

The best results could be achieved by combining the two instruments, e.g. using twinning projects for long term capacity building and creating partnerships with "sister" institutions, while using technical assistance to address very specific, ad-hoc, and short term needs. The best approach in fact is to use both instruments in complementary fashion. 


\section{Twinning Projects Portfolio in Macedonia}

Twinning projects in Macedonia have been introduced with CARDS 2000. During this initial stage 11 twinning projects in the total amount of $€ 13.69$ million have been implemented in the period August 2004 through June 2009. This stage has been completed with CARDS 2006 programming. The portfolio of projects in this period was focused primarily on approximation of legislation, particularly in internal market, competition policy, and labor. Several projects were designed around capacity building and supporting reforms in the Police and Police Academy, a number of institutions in charge of fighting criminal activities related to drugs, as well as the Public Prosecutor (organized crime and corruption department). Another important area that twinning projects have been focused on in this period include prevention of money laundering and in that sense capacity building of the Directorate for Prevention of Money Laundering, Ministry of Finance, and strengthening the system of public internal financial control. In addition, State Statistical Office and Ministry of Environment and Physical Planning have started a series of twinning projects that go through to IPA 2012-2013. The Sector for EU integration has implemented the first twinning project in Macedonia with a great success. Finally, the Commission for Protection of Competition has benefitted from a twinning project in this period.

Germany was the Member State partner for three out of eleven twinning projects, and Netherlands was the lead partner in two projects. The remaining projects were led by Slovenia, Hungary, Finland, Italy, Spain, and Slovakia (one project per each country). In addition, Slovenia, Austria, and Netherlands appeared as junior partners in consortium with other member states.

The very first twinning project in Macedonia made a huge success. Implemented in 2004-2005, it provided a real break-through experience for the Macedonian administration about the significance of the acquis and all steps that are necessary for the country to join the EU. The twinning partner, Slovenia, has been very enthusiastic in providing its very fresh pre-accession experience (completed in May 2004). Coming from the same country and sharing the same system in the past, the Slovenian counterparts provided very frank advice on the current situation and the ways forward in the EU accession process. It has been a very complex twinning project with a huge team ( 35 experts) coming in joint missions to assist various institutions in Macedonia. The main beneficiary institution was the Sector for EU integration, which coordinated the EU questionnaire process at that time and expected to start negotiations in 2006.

The next stage in using twinning programs is related to the IPA centralized system, when EU delegation was in charge of contracting, and it covers IPA 2007-2008 programming for component 1 - Transition Assistance and Institution Building. In this stage a total of 8 projects, including 2 light twinning projects, in the total amount of $€ 5.16$ million have been initiated. These projects have been created to support tax reform, building capacity for managing EU funds, public administration reform, decentralization process, public procurement, environmental management for central and local authorities, as well as democracy and fundamental rights. In addition, regulatory commission for energy has been supported within this period.

Eight member states have been involved as twinning partners including Austria, with 3 projects; France with 2 projects, Lithuania, Netherlands, Spain, Germany, Finland and Italy with 1 project each. In terms of sectors, the majority, or 5 projects have been related to public administration reforms, 2 with environment, and 1 with justice and home affairs. The implementation process of the first projects in this lot started in January 2010, and the last ones have been completed by May 2013.

The last stage started in 2010 when the EU Commission transferred its powers for IPA component 1 to the Macedonian authorities, and the country moved to the decentralized implementation system. The Central Financing and Contracting Department (CFCD) became the lead body of the operating structure and contracting authority for Macedonia for component 1 program - transition assistance and institution building (TAIB). Within IPA 2009 program, a total of 6 projects in the amount of $€ 5.86$ million have been initiated; 4 being successfully completed, while 2 being in implementation phase expected to be completed by December 2015. Four member states have been involved as lead twinning partners, Great Britain and Germany with 2 projects each, Finland and Italy with 1 project each, while Netherlands, Denmark and Italy have also been involved as junior twinning partners. Within IPA 2010 programming, a total of 10 projects in the amount of $€ 9.96$ million have been initiated, with five being in implementation phase, and five having contracts signed. Six member states have been involved as lead twinning partners, Austria, Germany, Spain and Slovenia with 2 projects each and Sweden and Italy with 1 project each. Hungary, Poland and Croatia have been also 
involved as junior twinning partners. Within IPA 2011 a total of 10 projects worth $€ 9.9$ million have been initiated with no project in implementation phase and only one having contract signed. One light twinning project aimed to support Tax Inspectorate in the amount of $€ 250,000$ has been cancelled due to the lack of interest from the member states. Within IPA 2012-2013 programming, 17 projects have been identified with a total amount of $€ 17.1$ million, but for one of the projects (aimed at assistance to the Ministry of Labor and Social Policy in prevention and protection against discrimination), the contractual mode has been modified to service contract instead of twinning.

In component 4 - Human Resources Development, five projects in the amount of $€ 7.39$ million have been implemented within IPA 2007-2009 programming. Main beneficiaries in this period include Ministry of Labor, Ministry of Education, CFCD, Center for Adult Education, Center for Vocational Education, and Bureau for Development of Education.

Six member states have been involved as twinning partners, including Austria with 2 projects, and Slovakia, Finland, Slovenia, France, and Spain with one project each. Within 2010 programming, two projects have been initiated in the total amount of $€ 1.45$ million. One of these projects has already been completed, while the second one, aimed at assisting Employment Service Agency, is still in implementation phase, due to be completed in June 2016. Germany and Lithuania are the main twinning partners for these projects. Decentralization of IPA management system for component 4 has been introduced in 2009 when the European Commission conferred management powers with ex ante control to the Macedonian authorities.

\section{Highlights of the Twinning Projects Portfolio}

In the last 15 years Macedonia has made a significant progress in using twinning projects. Starting with only one project in CARDS 2000, it has a portfolio of 67 projects that are at different stages of project cycle. In terms of the value of the projects, there is a positive trend of increasing the value of the twinning projects portfolio, with exception of the period of closing the CARDS program and entering into IPA funds use, when both the value and the number of projects have been decreased compared to previous years. Below is a picture showing the trend of increasing the value of twinning projects portfolio in the period 2000-2015.

Picture 1: Twinning Projects per Year in EUR

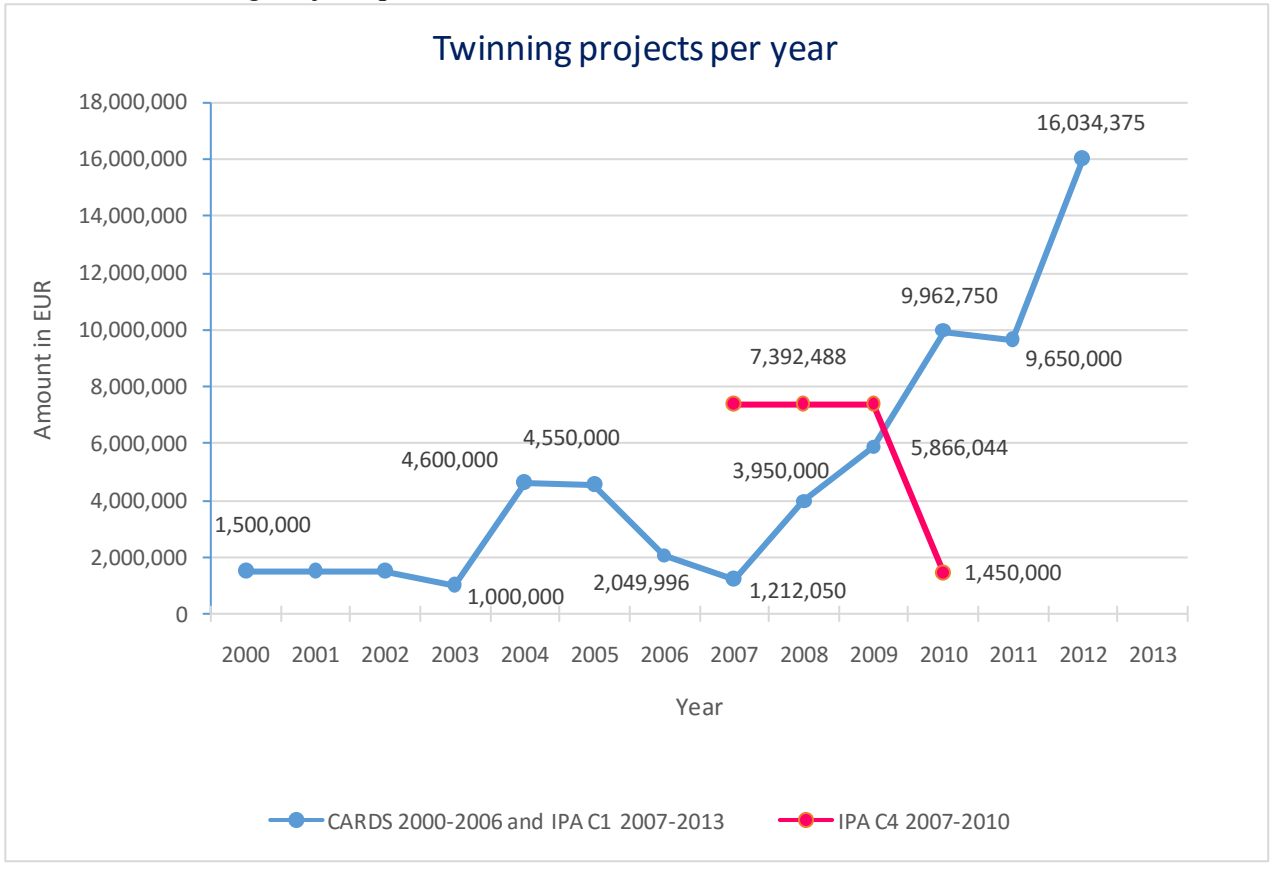


Similarly, the number of projects per year has equivalent upwards trend. Within a decade, Macedonia went from 1 or 2 projects per year to 10 projects in the recent years. This proves that the absorption capacity of the Macedonian institutions has been increased, as well as the management capacity of the IPA operating structure created in the last decade which now involves about 400 staff. The Central Financing and Contracting Department (CFCD) acts as a lead body of the operating structure for IPA component 1 and as contracting authority. The picture below displays the increasing trend of the number of twinning projects in Macedonia.

Picture 2: Number of Twinning Projects per Year

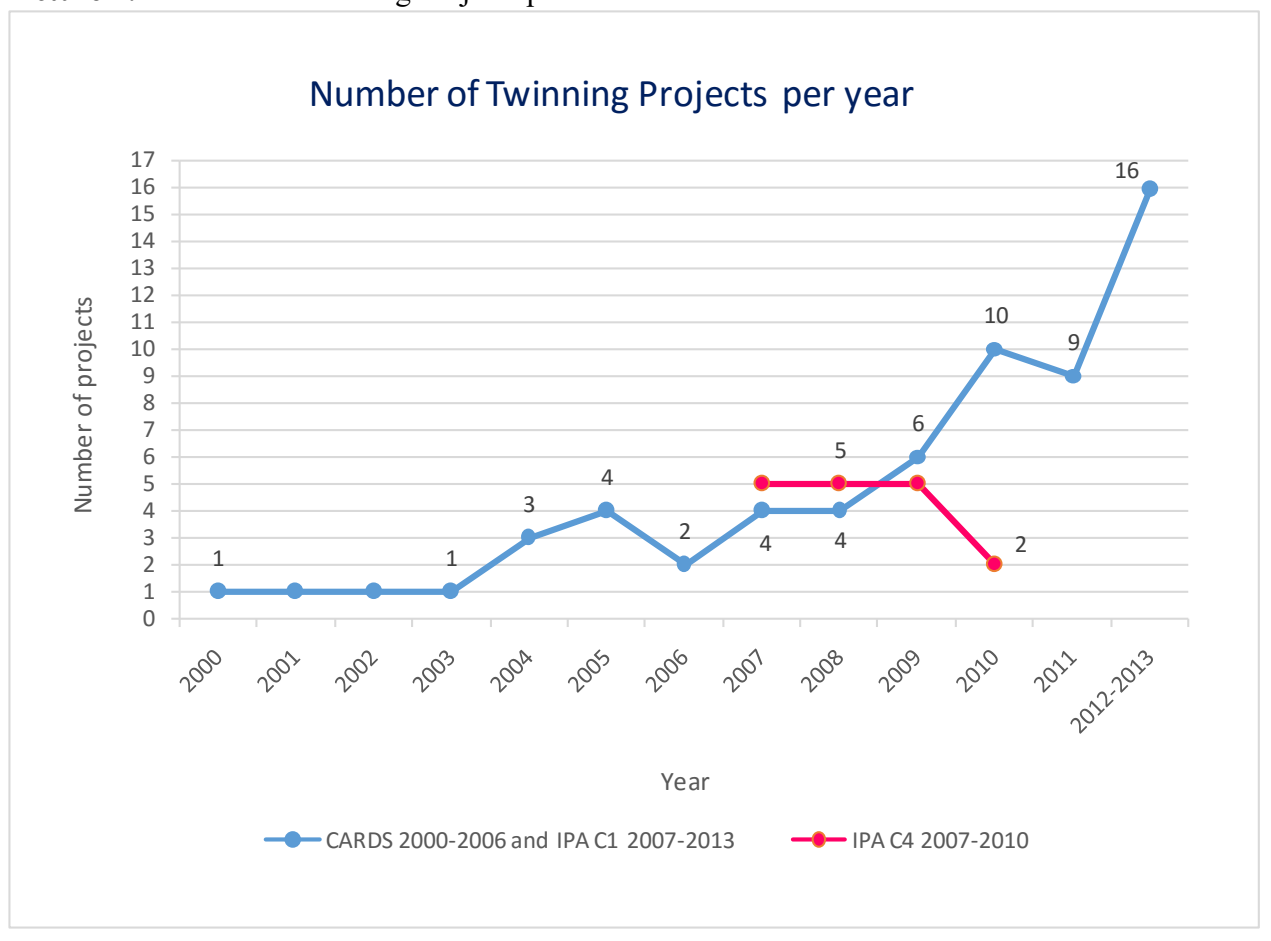

In terms of twinning partners, Macedonian institutions have been partnering with a wide array of member state institutions. In total, 19 member states have been actively involved in the twinning projects in Macedonia. The most active states in this sense have been Austria and Germany with 9 projects each, followed by Spain and Finland with 5 projects each, and Slovenia and Italy with 4 projects each. Five countries participated in the twinning projects in Macedonia as lead and junior partners, while six countries have been involved as junior partners only. Below is a picture showing the involvement of each member state in the twinning portfolio in Macedonia.

Picture 3: Member State Partners 


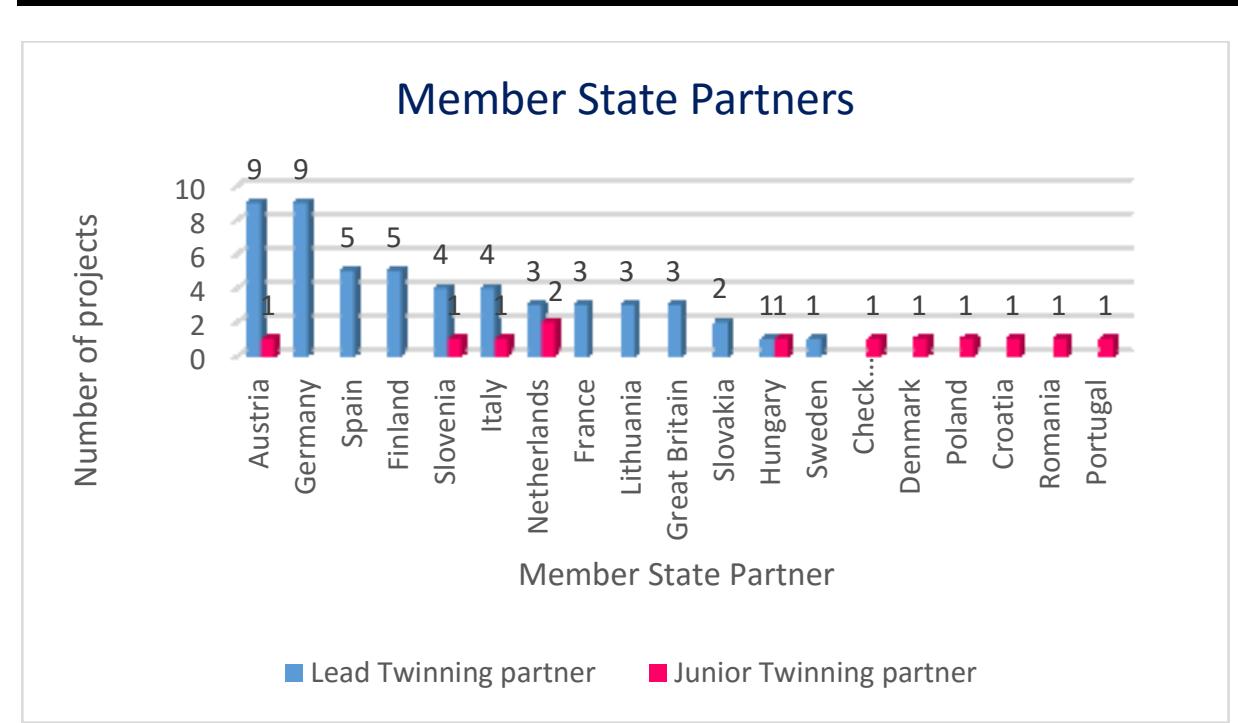

In terms of sectors, the majority of twinning projects in Macedonia are related to the public administration and justice and home affairs sectors -- 53.6 percent of the total number of projects. This is understandable given the efforts of the government to carry out public administration reform and approximation of legislation. Nine projects are related to environment, eight are related to the education and social affairs, seven are aimed at agriculture, while the least, six projects are related to economic development. Below is a picture of the twinning projects distribution by sector. Overall, a number of in-depth reforms have been initiated and carried out with the support of twinning program portfolio.

\section{Twinning projects by sectors}

- Justice and Home Affairs
- Public Administration Reforms
= Environment
- Economic Development
- Education, Employment and
Social Affairs
- Agriculture

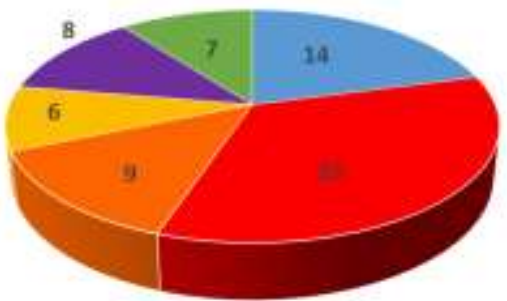

\section{Conclusions}

In the last 15 years Macedonia has benefitted a lot from a number of successful twinning projects. Benefits from the twinning program include capacity building, developing a body of knowledge of the beneficiary institution, building a long term relationship with a "sister" institution, introducing 
new methodologies, changing the organization and mindset of the employees, etc. Still, in spite of the overall improvements, both the preparation and implementation of the twinning and technical assistance projects in Macedonia are still associated with a lot of bureaucratic and cumbersome delays. For instance, for most of the EU funded projects there is a typical gap of three years between programming and project implementation. This is mostly a result of the project designing procedure which starts when the final deadline for submitting the project fiche (or TOR) is getting very close. To avoid the typical gap of three years between programming and project implementation, it is recommended to treat the project preparation deadline as final deadline, instead of taking it for a required schedule. The project design process could start much earlier than the programming deadline, so it is a matter of improved planning and allocation of resources to prepare the projects well in advance of the final deadline, e.g when the timing of the project implementation is the most appropriate. In addition, to address the delays related to the bureaucratic burdens, there is a room for improved coordination between the beneficiary institution, CFCD, Secretariat for European Affairs, and EU delegation.

\section{References:}

1. European Commission, Institution Building in the Framework of European Union Policies, Common Twinning Manual Revision 2012

2. CFCD Twinning Contracts Under IPA Component 1 National Program 2009 http://cfcd.finance.gov.mk/wp-content/uploads/2013/07/IPA-Programme-TAIB-2009Twinning.pdf

3. CFCD Twinning Contracts Under IPA Component 1 National Program 2010 2009http://cfcd.finance.gov.mk/wp-content/uploads/2013/07/IPA-Programme-TAIB-2010Twinning.pdf

4. CFCD Twinning Contracts Under IPA Component IV Program 2007-2013 http://cfcd.finance.gov.mk/wp-content/uploads/2013/07/IPA-Programme-HRD-2007-2013Twinning.pdf

5. Secretariat for European affairs- IPA Projects http://www.sep.gov.mk/channel/?ID=82

6. http://ec.europa.eu/enlargement/tenders/twinning/index_en.htm 